\title{
Airway epithelial cell exposure to distinct e-cigarette liquid flavorings reveals toxicity thresholds and activation of CFTR by the chocolate flavoring 2,5-dimethypyrazine
}

Cara L. Sherwood ${ }^{1,2^{*}}$ and Scott Boitano $1,2,3$

\begin{abstract}
Background: The potential for adverse respiratory effects following exposure to electronic (e-) cigarette liquid (e-liquid) flavorings remains largely unexplored. Given the multitude of flavor permutations on the market, identification of those flavor constituents that negatively impact the respiratory tract is a daunting task. In this study we examined the impact of common e-liquid flavoring chemicals on the airway epithelium, the cellular monolayer that provides the first line of defense against inhaled particulates, pathogens, and toxicants.
\end{abstract}

Methods: We used the xCELLigence real-time cell analyzer (RTCA) as a primary high-capacity screening tool to assess cytotoxicity thresholds and physiological effects of common e-liquid flavoring chemicals on immortalized human bronchial epithelial cells (16HBE140-). The RTCA was used secondarily to assess the capability of 16HBE140- cells to respond to cellular signaling agonists following a $24 \mathrm{~h}$ exposure to select flavoring chemicals. Finally, we conducted biophysical measurements of well-differentiated primary mouse tracheal epithelial (MTE) cells with an Ussing chamber to measure the effects of e-cigarette flavoring constituents on barrier function and ion conductance.

Results: In our high-capacity screens five of the seven flavoring chemicals displayed changes in cellular impedance consistent with cell death at concentrations found in e-liquid. Vanillin and the chocolate flavoring 2,5-dimethylpyrazine caused alterations in cellular physiology indicative of a cellular signaling event. At subcytotoxic levels, $24 \mathrm{~h}$ exposure to 2,5-dimethylpyrazine compromised the ability of airway epithelial cells to respond to signaling agonists important in salt and water balance at the airway surface. Biophysical measurements of 2,5-dimethylpyrazine on primary MTE cells revealed alterations in ion conductance consistent with an efflux at the apical airway surface that was accompanied by a transient loss in transepithelial resistance. Mechanistic studies confirmed that the increases in ion conductance evoked by 2,5-dimethylpyrazine were largely attributed to a protein kinase A-dependent (PKA) activation of the cystic fibrosis transmembrane conductance regulator (CFTR) ion channel.

Conclusions: Data from our high-capacity screening assays demonstrates that individual e-cigarette liquid flavoring chemicals vary in their cytotoxicity profiles and that some constituents evoke a cellular physiological response on their own independent of cell death. The activation of CFTR by 2,5-dimethylpyrazine may have detrimental consequences for airway surface liquid homeostasis in individuals that use e-cigarettes habitually.

Keywords: Electronic cigarettes, Airway epithelium, CFTR, Odorant receptor, 2,5-dimethylpyrazine, xCELLigence RTCA

\footnotetext{
*Correspondence: caras@email.arizona.edu

${ }^{1}$ Asthma and Airway Disease Research Center, Arizona Health Sciences

Center, 1501 N. Campbell Avenue, Tucson, AZ 85724-5030, USA

${ }^{2}$ Bio5 Collaborative Research Institute, Arizona Health Sciences Center,

Tucson, AZ, USA

Full list of author information is available at the end of the article
} 


\section{Background}

Electronic (e-) cigarettes are the most common type of electronic nicotine delivery systems (ENDS) that simulate smoking independent of the combustion of tobacco. The global market for ENDS has rapidly expanded and it is predicted that within the next decade, sales of ENDS will surpass that of conventional combustible tobacco cigarettes [1]. In the U.S. market alone e-cigarette sales are estimated to be $\$ 10$ billion by 2017 [2]. As of 2014 there were $>450$ distinct e-cigarette products with $>7500$ flavor variations available for sale online and/or at retail outlets worldwide [3-6]. Despite the rapid increase in popularity of ENDS the potential for harmful respiratory effects following use of these products remains largely unexplored.

In their simplest form e-cigarettes contain a fluid-filled (e-liquid) cartridge with a battery-powered atomizer. E-liquid comes in a vast variety of configurations and can contain numerous ingredients including vegetable glycerin (VG) responsible for the visible vapor, the humectant propylene glycol (PG), nicotine, menthol and/or other flavorings. Although an early study of e-cigarettes suggested that the levels of several harmful constituents are lower in e-cigarette aerosols when compared with cigarette smoke [7], some constituents unique to ecigarette aerosols, namely flavorings, have been shown to be cytotoxic in cell models [8].

Research in to the composition and concentration of flavorings in e-liquids is just beginning [9-11]. E-liquid flavorings are often advertised as "safe" because they are approved for ingestion. However, the airway and the gastrointestinal tract are quite distinct and represent significantly different toxicity susceptibilities. A cautionary example that illustrates this point is the toxicity fate of diacetyl, an early component of artificial butter popcorn flavoring. Despite being approved for ingestion, excessive inhalation exposure of diacetyl to lung tissue results in bronchiolitis obliterans, a rare and irreversible lung disease [12]. The potential for e-liquid flavoring chemicals to cause detrimental health effects warrants their investigation [13].

The conducting airway epithelium provides the first line of defense against inhaled particulates, pathogens, allergens, and other noxious agents [14]. The varied epithelial cell types along the conducting airway provide key innate immune functions including: a physical barrier to protect the underlying tissue; salt and water movement to maintain a hydrated lumen; a mucociliary escalator to coordinate particulate filtering; and secretion of multiple defense factors such as antimicrobials. These functions of airway epithelial innate immunity are facilitated by signal transduction molecules such as ATP and cAMP. A compromised airway epithelium can lead to infection, inflammation and airway remodeling associated with the onset and pathogenesis of chronic lung disease (reviewed in [15-19]). Because e-cigarette aerosols are delivered directly to the airway a logical place to initiate toxicity studies is with airway epithelial cell models.

In this study we used high-capacity real-time cell analysis as a primary screen to identify toxicity thresholds of e-liquid flavorings on human bronchial epithelial cells (16HBE14o-). Because cells can contribute to disease in lieu of cell death, we also used high-capacity real-time cell analysis to measure responses to cellular signaling molecules (i.e., ATP and forskolin-induced cAMP) following exposure to subcytotoxic levels of e-liquid flavoring chemicals. From the cytotoxic and subcytotoxic profiles established, we selected 2,5dimethylpyrazine for more thorough mechanistic studies. From biophysical analyses we showed a direct effect of 2,5-dimethylpyrazine on the regulation of $\mathrm{Cl}^{-}$secretion. These findings confirm the need for high-capacity toxicity screening that can lead to mechanistic understanding to better predict risks associated with the rapidly growing e-cigarette products.

\section{Methods \\ Materials}

Cellgro DMEM:F12 was from Mediatech (Manassas, VA). Lechner and LaVeck basal media (LHC), Hanks' Balanced Saline Solution, glutamax, penicillin, and streptomycin were from Life Technologies (Carlsbad, $\mathrm{CA}$ ). Fibronectin, type I collagen, and $\mathrm{Nu}-\mathrm{Serum}^{\mathrm{Ts}}$ were from Becton-Dickinson (Franklin Lakes, NJ). Minimum Essential Medium with Earle's salts (MEM), Fetal Bovine Serum (FBS), 2,5-dimethylpyrazine, amiloride, damascenone, forskolin, linalool, $\alpha$-ionone, ethyl maltol, furaneol and vanillin were from Sigma-Aldrich (St. Louis, MO). CFTR-172 inh and 8-bromo-cAMP were from Tocris Bioscience (Bristol, UK). Semipermeable filters were Corning Costar $6.5 \mathrm{~mm}^{\text {Transwell }^{\odot}}$ with $0.4 \mu \mathrm{m}$ Pore Polyester Membrane Insert, sterile (Lowell, MA). All other chemicals were from Sigma-Aldrich or Fisher Scientific (Pittsburgh, PA).

\section{Immortalized human bronchial epithelial cell culture methods}

16HBE14o- cells, a SV40 transformed human bronchial epithelial cell line [20], were obtained through the California Pacific Medical Center Research Institute (San Francisco, CA, USA). Growth conditions for 16HBE14ocells have been described [21, 22]. 16HBE14o- cells were grown on a collagen/fibronectin/BSA (CFB) matrix. Cells were expanded in flasks and passaged onto E-plates (ACEA Biosciences, San Diego, CA) at 40,000 cells per well for high-capacity real-time cell analysis. 


\section{Primary Mouse Tracheal Epithelial (MTE) cell culture methods}

Animal protocols were approved by the Institutional Animal Care and Use Committee of The University of Arizona. Primary MTE cells were chosen for Ussing chamber studies because they are representative of a polarized epithelium necessary for biophysical measurements. C57Bl/6 wild type mice were used for these cells that were cultured as previously described [23]. MTE cells were seeded onto $6.5 \mathrm{~mm}$ semipermeable filters coated with CFB matrix and cultured at $37{ }^{\circ} \mathrm{C}$ with $5 \%$ $\mathrm{CO}_{2}$. After cell monolayers reached a transepithelial resistance of $>500 \Omega \cdot \mathrm{cm}^{2}(\sim 5$ days $)$ the apical media was removed to establish an air/liquid interface (ALI). These cells become a mixed population of well-differentiated cells with clearly established cilia after $\sim 5$ days at ALI. Cells were used for experimentation 2-3 weeks after differentiation was established.

\section{xCELLigence real time cell analyzer toxicity and cell signaling assays}

Methods for high-capacity real-time cell analysis of toxicity and physiological responses have been described $[21,24]$ and the measurement of cytotoxicity validated in 16HBE14o- cells [25]. 16HBE14o- cells were plated in full culture medium onto 96 well E-plates coated with CFB solution and allowed to grow at $37{ }^{\circ} \mathrm{C}$ and $5 \% \mathrm{CO}_{2}$ while impedance at the well surface was continuously monitored [26, 27]. As per manufacturer's instructions (ACEA Biosciences, San Diego, CA), relative impedance is expressed as a Cell Index where: Cell Index $=\left(\mathrm{Z}_{\mathrm{i}}-\mathrm{Z}_{0}\right) /$ $15 \Omega$; and $Z_{i}$ is impedance at a given time point during the experiment (i.e., post ATP addition), and $Z_{0}$ is impedance before the addition of agonist. For reference, a dramatic decrease in impedance can be indicative of cell death whereas activation of $\mathrm{GPCR} / \mathrm{G}_{\mathrm{q}}$, such as occurs following ATP activation of purinergic receptors, results in an increase in Cell Index [21]. To determine toxicity thresholds cells were grown overnight on an E-plate and then exposed to varying doses of e-liquid flavoring chemicals diluted in full culture medium. Cell Index responses to e-liquid flavorings were recorded every $15 \mathrm{~min}$ for $24 \mathrm{~h}$. Physiological responses to ATP and forskolin were recorded every $30 \mathrm{~s}$ for $4 \mathrm{~h}$ following a $24 \mathrm{~h}$ exposure to select e-liquid flavorings. Cell responses were collected in triplicate or quadruplicate. To better compare readings, cell responses were adjusted to a baseline by taking the ratio of recordings from cells in culture medium alone and then normalizing at the time point of e-liquid flavoring or cell signaling agonist addition as described in supplemental figure S2 in [28]. E-liquid flavoring chemicals screened with highcapacity real-time cell analysis were based on those from popular brands such as blu and GreenSmoke e-cigarette cartridges with distinct organoleptic properties including: 2,5-dimethylpyarzine (chocolate, nutty flavor); damascenone (apple, citrus, wine-like); linalool (floral, spice); $\alpha$-ionone (fruity, raspberry); ethyl maltol (caramel); furaneol (strawberry, sweet); and vanillin (vanilla) [29, 30].

\section{MTS cytotoxicity assay}

16HBE14o- cells were seeded on a tissue culture treated 96-well plate coated with CFB at a density of 40,000 cells/well. Cells were grown overnight and then treated with e-liquid flavoring chemicals diluted in MEM. Following a 24-h exposure to the e-liquid chemicals cytotoxicity was assessed using a CellTiter $96^{\circ}$ AQueous Non-Radioactive Cell Proliferation Assay (MTS; Promega, Madison, WI). MTS dye was added to all wells at a 1:10 dilution and allowed to incubate at $37{ }^{\circ} \mathrm{C}$ in $5 \% \mathrm{CO}_{2}$ for $1.5 \mathrm{~h}$. The 96 -well plate was then shaken vigorously and read in a Synergy ${ }^{\text {TM }}$ HTX Multi-Mode Microplate Reader (BioTek, Winooski, VT) at an absorbance of $490 \mathrm{~nm}$.

\section{Ussing chamber studies}

MTE cells on $6.5 \mathrm{~mm}$ permeable filters were mounted in an EasyMount Ussing chamber system (Physiologic Instruments, San Diego, CA) and bathed on both sides with Krebs-Ringers Buffer containing: $115 \mathrm{mM} \mathrm{NaCl}$, $25 \mathrm{mM} \mathrm{NaHCO} 3,0.4 \mathrm{mM} \mathrm{KH} \mathrm{PO}_{4}, 2.4 \mathrm{mM} \mathrm{K}_{2} \mathrm{HPO}_{4}$, $1.2 \mathrm{mM} \mathrm{CaCl}_{2}$, and $1.2 \mathrm{mM} \mathrm{MgCl}$ with $10 \mathrm{mM}$ glucose. Bath solutions were continuously circulated with a gas lift by bubbling with $95 \%$ air and $5 \% \mathrm{CO}_{2}$ at $37{ }^{\circ} \mathrm{C}$ (pH 7.4). MTE cell monolayers were voltage clamped and monitored for changes in short-circuit current $\left(\mathrm{I}_{\mathrm{sc}}\right)$ and TER with a multichannel voltage/current clamp VCC MC8 (Physiologic Instruments, San Diego, CA). MTE cell monolayers were clamped to $0 \mathrm{mV}$ and a $5 \mathrm{mV}$ pulse of 200-msec duration was imposed every $10 \mathrm{~s}$. Changes in $\mathrm{I}_{\mathrm{sc}}\left(\Delta \mathrm{I}_{\mathrm{sc}}\right)$ were calculated from the difference between the initial $I_{\mathrm{sc}}$ measurement at baseline and the peak measurement change after adding 2,5dimethylpyrazine alone or in combination with pharmacological inhibitors/agonists. Data was analyzed using Acquire and Analyze software, version 2.3 (Physiologic Instruments, San Diego, CA).

\section{Statistics}

One-way ANOVA with a Dunnett's Multiple Comparison Test was used for statistical analysis unless otherwise noted. A value of $P<0.05$ was used to establish significant differences between data sets. Figures are graphed \pm standard error of the mean (SEM) unless otherwise noted. 


\section{Results}

High-capacity real-time cell analysis reveals toxicity thresholds of e-liquid flavorings

Elucidating e-liquid flavorings that pose potential risks to lung health is challenging given the vast array of available flavoring chemical constituents. To address this barrier we used high-capacity real-time cell analysis on a human bronchial epithelial cell line (16HBE14o) with multiple e-liquid flavoring chemicals. We screened seven flavoring chemicals present in e-liquid cartridges from popular e-cigarette brands (i.e., Blu, GreenSmoke ${ }^{\odot}$ [29, 30]. Four of the flavorings (Fig. 1a-d) were tested with the highest concentration representing the percent volume/volume $(\% \mathrm{v} / \mathrm{v})$ present in
GreenSmoke ${ }^{\oplus}$ e-cigarette cartridges and three flavorings (Fig. 1e-g) were tested starting at a concentration one-tenth (due to solubility issues) the \% v/v present in GreenSmoke e-cigarette cartridges. All flavorings were screened at multiple concentrations in quadruplicate.

In five of the seven compounds tested the highest concentration(s) displayed a loss of cell index consistent with cytotoxicity (Fig. 1a-e). We confirmed the loss of cell index was due to cytotoxicity with an MTS assay. In the MTS assay we compared those e-liquid chemical concentrations that showed cytotoxicity in the RTCA with the same flavor chemicals at a concentration that did not display cytotoxicity in the RTCA (Fig. 1h).
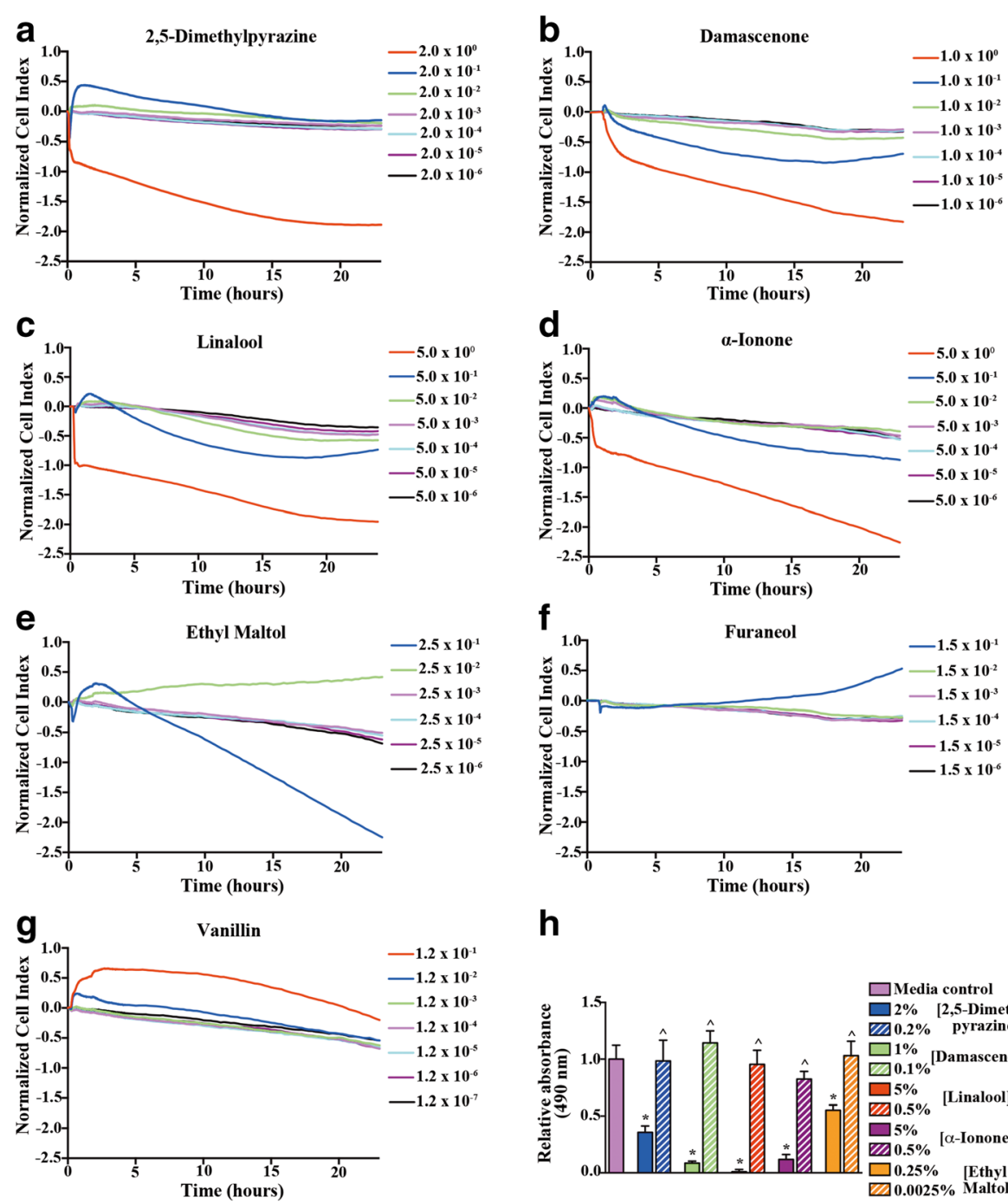

h

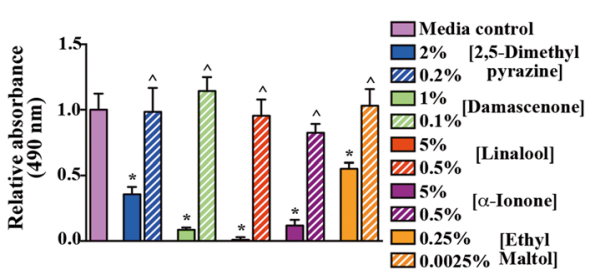

Fig. 1 High-capacity real-time cellular analysis reveals toxicity thresholds of e-liquid flavorings. The toxicity thresholds of individual e-cigarette liquid flavoring constituents on 16HBE140- cells was determined by cellular impedance changes over $24 \mathrm{~h}$. a-d The highest concentration of each flavoring constituent was representative of the $\% \mathrm{v} / \mathrm{v}$ present in e-cigarette liquid. e-g The highest concentration of each flavoring constituent represented $1 /$ 10 th the $\% \mathrm{v} / \mathrm{v}$ present in e-cigarette liquid. All flavors except furaneol (f) and vanillin ( $\mathbf{g}$ ) displayed cell index changes consistent with cytotoxicity that was validated with an MTS assay (h). *indicates significant difference from control cells and $\wedge$ indicates significant difference between concentrations of the same flavoring, $P<0.05$ in a one-way ANOVA with a Tukey's Multiple Comparison Test 
Furaneol (Fig. 1f) and vanillin (Fig. 1g) did not display any cell index changes consistent with cell death; however, the cell index for the full concentration present in e-liquid for these compounds could not be tested due to solubility issues. In addition to cytotoxicity responses at the higher concentrations, at dilutions to one-tenth the amount present in e-liquid, 2,5-dimethylpyrazine and vanillin displayed increases in cell index consistent with a cell-signaling event. Because of the unique combination of cytotoxicity and cellular signaling exhibited by 2,5-dimethylpyrazine we selected this compound from the initial screen for further toxicity studies.

\section{2,5-Dimethylpyrazine reduces the physiological response} to signaling molecules important in aspects of airway epithelial cell innate immunity

We conducted a secondary high-capacity real-time cell analysis screen of 2,5-dimethylpyrazine to examine in finer detail the signaling pattern elicited by $16 \mathrm{HBE} 14 \mathrm{o}-$ cells upon exposure (Fig. 2a). Concentrations of 2,5dimethylpyrazine as low as $0.02 \% \mathrm{v} / \mathrm{v}(1 / 100$ of what is in e-liquid) induced distinct cellular impedance changes indicative of a cellular signaling event. Additionally, we tested the capability of $16 \mathrm{HBE} 14 \mathrm{o}-$ cells to respond to cAMP (via forskolin) or exogenous ATP, important signaling molecules in airway epithelial cell physiology (e.g., mucociliary clearance), following exposure to 2,5-dimethylpyrazine (Fig. 2b-c). 16HBE14o- cells were treated for $24 \mathrm{~h}$ with subcytotoxic concentrations of 2,5dimethylpyrazine followed by exposure to either forskolin $(10 \mu \mathrm{M}$; to raise cAMP) or exogenous ATP $(3 \mu \mathrm{M}$; to raise intracellular $\mathrm{Ca}^{2+}$ concentration) and cellular impedance monitored. Compared to untreated cells, cells that were treated for $24 \mathrm{~h}$ with 2,5-dimethylpyrazine displayed a concentration-dependent reduction in physiological response to both forskolin (Fig. 2b) and to ATP (Fig. 2c). We concluded that 2,5-dimethylpyrazine alters the capability of airway epithelial cells to respond to signaling molecules key in the proper functioning of airway cell physiology.

\section{2,5-Dimethylpyrazine increases airway epithelial ion conductance}

In order to determine the impact of 2,5-dimethylpyrazine on airway epithelial ion conductance and barrier function we conducted Ussing chamber studies. Welldifferentiated primary mouse tracheal epithelial (MTE) cells that retain characteristics such as polarization needed for biophysical measurements were mounted in Ussing chambers and voltage clamped for measurement of ion conductance [short circuit current $\left(\mathrm{I}_{\mathrm{sc}}\right)$ ] and transepithelial resistance (TER). When administered in the apical chamber (i.e., luminal side of the epithelium) 2,5dimethylpyrazine induced an apical ion efflux (Fig. 3a)

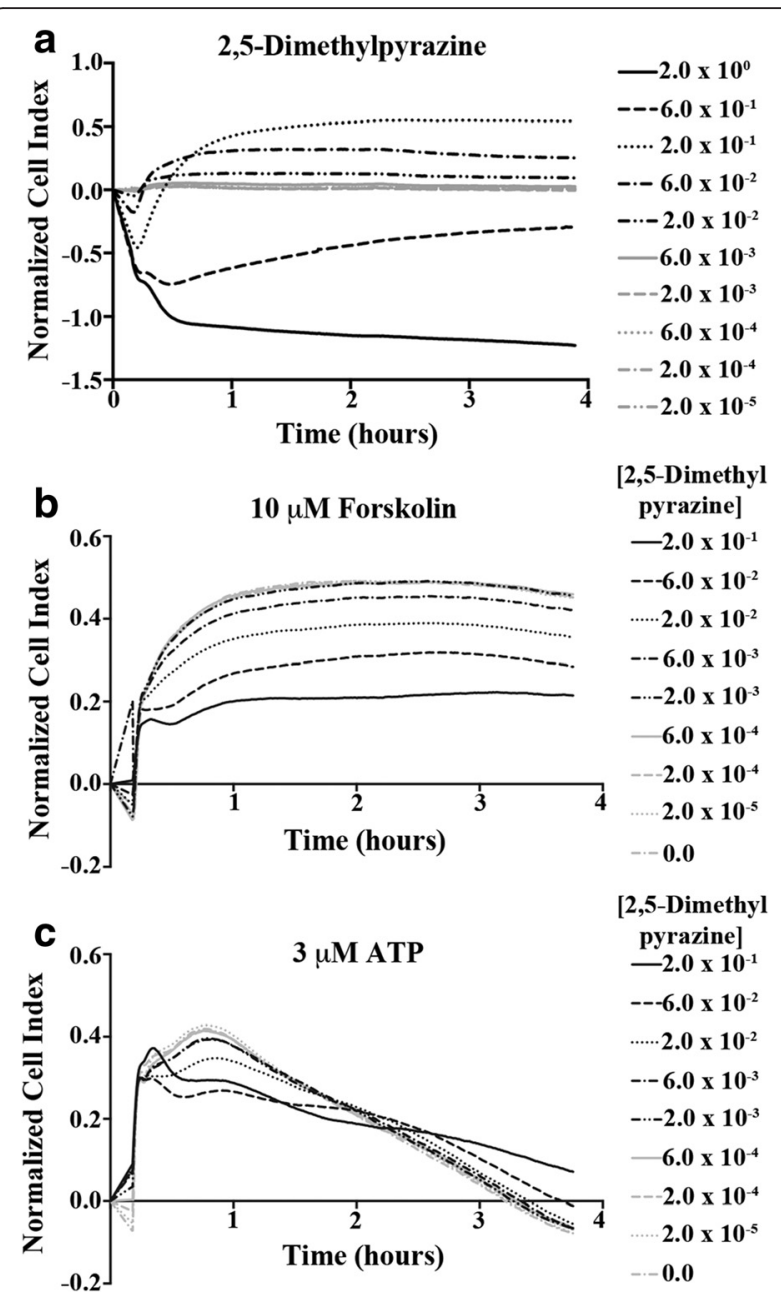

Fig. 2 2,5-Dimethylpyrazine reduces the physiological response to cellular signaling critical in airway innate immunity. a 16HBE14O- cells display cytotoxic cellular impedance responses to 2,5-dimethylpyrazine at $0.6 \%$ and higher. b A 24 h exposure to subcytotoxic concentrations of 2,5-dimethylpyrazine causes a concentration-dependent signaling response to forskolin in 16HBE14o- cells. c A $24 \mathrm{~h}$ exposure to subcytotoxic concentrations of 2,5-dimethylpyrazine results in a reduction in $16 \mathrm{HBE} 14 \mathrm{O}$ - signaling response to ATP. At subcytotoxic concentrations, 2,5-dimethylpyrazine evoked a physiological response at concentrations as low as $0.06 \% \mathrm{v} / \mathrm{v}$ and dampened the response to cellular signaling key in airway epithelial innate immunity

that was accompanied by a transient loss in TER (Fig. 3c). Application of multiple concentrations of 2,5dimethylpyrazine resulted in an $\mathrm{I}_{\mathrm{sc}} \mathrm{EC}_{50} \sim 1 / 100$ th of the concentration found in GreenSmoke ${ }^{\ominus}$ e-liquid (Fig. 3b; $\mathrm{EC}_{50}=0.021 \% \mathrm{v} / \mathrm{v} 95 \%$ Confidence Interval: 0.0085 to $0.053 \% \mathrm{v} / \mathrm{v})$.

\section{2,5-Dimethylpyrazine activates apical ion efflux via cystic fibrosis transmembrane conductance regulator (CFTR)} It is known that 2,5-dimethylpyrazine is an odorant compound found in dark chocolate [31]. Odorants can 

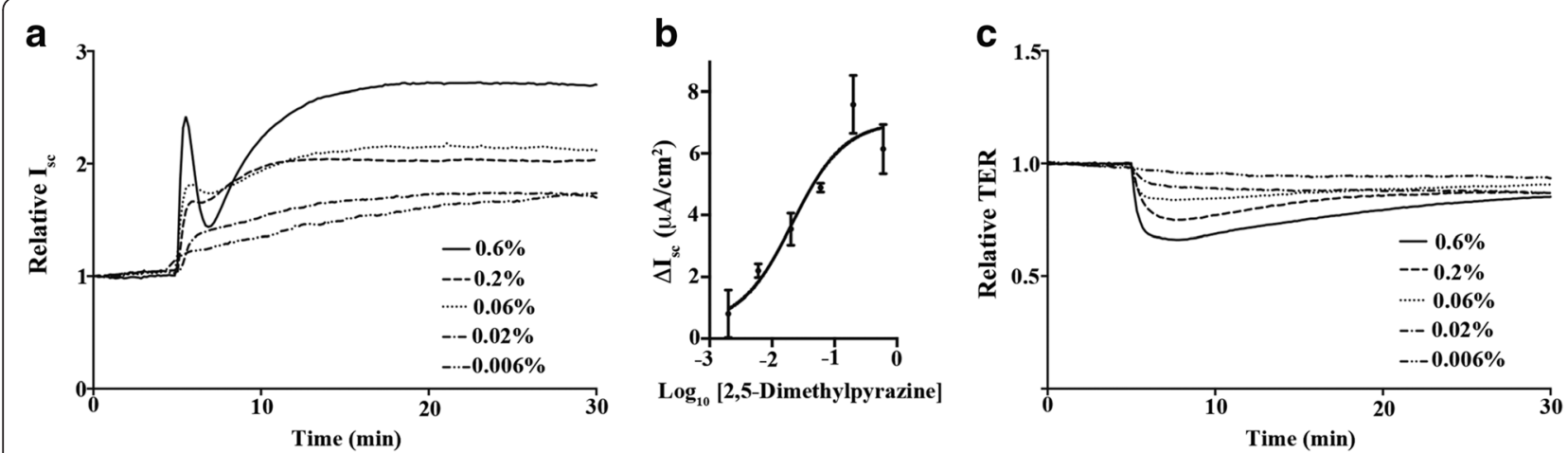

Fig. 3 2,5-Dimethylpyrazine increases airway epithelial ion conductance. Primary MTE cells were voltage clamped in Ussing chambers and monitored for changes in $I_{s c}$ and TER following varying doses of 2,5-dimethylpyrazine. a Representative traces of $I_{s c}$ in response to 2,5-dimethylpyrazine demonstrate a concentration dependent increase in $I_{s c}$. b A concentration-dependent curve of the change in $I_{s c}$ following 2,5-dimethylpyrazine. c Representative traces of TER in response to varying concentrations of 2,5-dimethylpyrazine demonstrate a concentration dependent drop in TER. Addition of 2,5-dimethylpyrazine on the apical airway epithelial surface results in an increase in apical ion efflux with a concurrent drop in TER

bind a class of $\mathrm{G}$ protein-coupled receptors that initiate an adenylyl cyclase-signaling cascade [32, 33]. Since airway epithelial cells express CFTR on their apical surface we tested the hypothesis that observed 2,5-dimethylpyrazine increases in $\mathrm{I}_{\mathrm{sc}}$ (Fig. 3) were due to CFTR-mediated $\mathrm{Cl}^{-}$conductance resulting from increased levels of cAMP downstream of odorant receptor activation. We conducted Ussing chamber studies under voltage clamp conditions with $0.2 \% \mathrm{v} / \mathrm{v}$ 2,5-dimethylpyrazine, a subcytotoxic concentration that showed signaling activity in high-capacity real-time cell analysis and Ussing chamber studies, to evaluate the effects of pharmacological blockers/agonists in the cAMP/CFTR signaling cascade.

In the first experiment, we pre-treated MTE cell cultures with the epithelial sodium channel blocker amiloride (10 $\mu \mathrm{M}$; Fig. 4a-b dashed arrow) followed by apical addition of CFTR blocker CFTR-172 inh $(20 \mu \mathrm{M}$; Fig. 4a-b dotted arrow). These cells were then exposed to apical addition of 2,5-dimethylpyrazine $(0.2 \% \mathrm{v} / \mathrm{v}$; Fig. 4a-b solid arrow) while monitoring $\mathrm{I}_{\mathrm{sc}}$ and TER. The peak change in $I_{s c}$ and TER evoked by 2,5dimethylpyrazine in MTE cells pre-treated with amiloride and CFTR-172 inh (Fig. 4a-b dotted traces) was significantly reduced [Fig. $4 \mathrm{a}-\mathrm{b} ; \Delta \mathrm{I}_{\mathrm{sc}}: 2.0 \pm 0.46 \mu \mathrm{A} / \mathrm{cm}^{2}(n=4)$; $\Delta$ TER: $\left.67.6 \pm 4.0 \Omega \cdot \mathrm{cm}^{2}(n=4)\right]$ compared to those treated with only amiloride and 2,5-dimethylpyrazine [Fig. 4a-b solid traces; $\Delta \mathrm{I}_{\mathrm{sc}}: 7.7 \pm 0.69 \mu \mathrm{A} / \mathrm{cm}^{2}(n=3)$; $\triangle$ TER: $\left.121.7 \pm 27.6 \Omega \cdot \mathrm{cm}^{2}(n=3)\right]$.

In order to confirm that 2,5-dimethylpyrazine was acting through a cAMP-protein kinase A (PKA) signaling cascade, and not by directly activating CFTR, we used the PKA blocker H89. MTE cells were monitored for response to 2,5-dimethylpyrazine $(0.2 \% \mathrm{v} / \mathrm{v}$; Fig. 5a-b solid arrow) following a $30 \mathrm{~min}$ pre-treatment with H89 $(10 \mu \mathrm{M})$ and amiloride (10 $\mu \mathrm{M}$; Fig. 5a-b dashed arrow). Representative $\mathrm{I}_{\mathrm{sc}}$ and TER traces (dotted lines) for the blocking experiment are shown in Fig. 5a-b. The peak change in $I_{\mathrm{sc}}$ and TER evoked by 2,5-dimethylpyrazine in MTE cells pretreated with $\mathrm{H} 89$ [(Fig. 5a-b; $\Delta \mathrm{I}_{\mathrm{sc}}: 1.8 \pm$ $0.12 \mu \mathrm{A} / \mathrm{cm}^{2}(n=3) ; \Delta$ TER: $\left.53.7 \pm 10.8 \Omega \cdot \mathrm{cm}^{2}(n=3)\right]$ was significantly reduced compared to controls.

To test if an increase in intracellular cAMP concentration was necessary for the 2,5-dimethylpyrazine activation of CFTR in MTE cells, we administered the cAMP analog 8-bromo-cAMP (100 $\mu$ M; Fig. 6a-b dotted arrow) to MTE cell cultures under current clamp conditions prior to the addition of 2,5-dimethylpyrazine. Following 8-bromocAMP addition, and upon $I_{\mathrm{sc}}$ and TER stabilization, we added amiloride (10 $\mu \mathrm{M}$; Fig. 6a-b dashed arrow) and then 2,5-dimethypyrazine $(0.2 \% \mathrm{v} / \mathrm{v}$; Fig. 6a-b solid arrow). Representative $I_{\mathrm{sc}}$ and TER traces (dotted lines) for this experiment are shown in Fig. 6a-b. The peak change in $\mathrm{I}_{\mathrm{sc}}$ and TER evoked by 2,5-dimethylpyrazine in MTE cells pretreated with 8-bromo-cAMP and amiloride (Fig. 6a-b; $\Delta \mathrm{I}_{\mathrm{sc}}: 0.8 \pm 0.05 \mu \mathrm{A} / \mathrm{cm}^{2}(n=3) ; \Delta$ TER: $22.2 \pm 4.8 \Omega \cdot \mathrm{cm}^{2}$ $(n=3)$ was significantly reduced compared to controls. The addition of intracellular 8-bromo-cAMP significantly attenuated the changes in $\mathrm{I}_{\mathrm{sc}}$ and TER evoked by 2,5dimethylpyrazine, supporting the hypothesis that 2,5dimethylpyrazine leads to increased levels of cellular cAMP to alter $\mathrm{I}_{\mathrm{sc}}$. From these experiments we conclude that 2,5-dimethylpyrazine increases apical $\mathrm{Cl}^{-}$efflux in primary airway epithelial cells via CFTR, and that activation of CFTR is through a cAMP-PKA signaling cascade.

\section{Discussion}

In this study we used a high-capacity validated screen to examine concentration-dependent cytotoxicity from seven common e-cigarette flavorings in order to assess their safety in the airway. In addition to identifying cytotoxicity thresholds for five of the seven chemicals tested, we were able to identify two compounds, 2,5-dimethylpyrazine and 

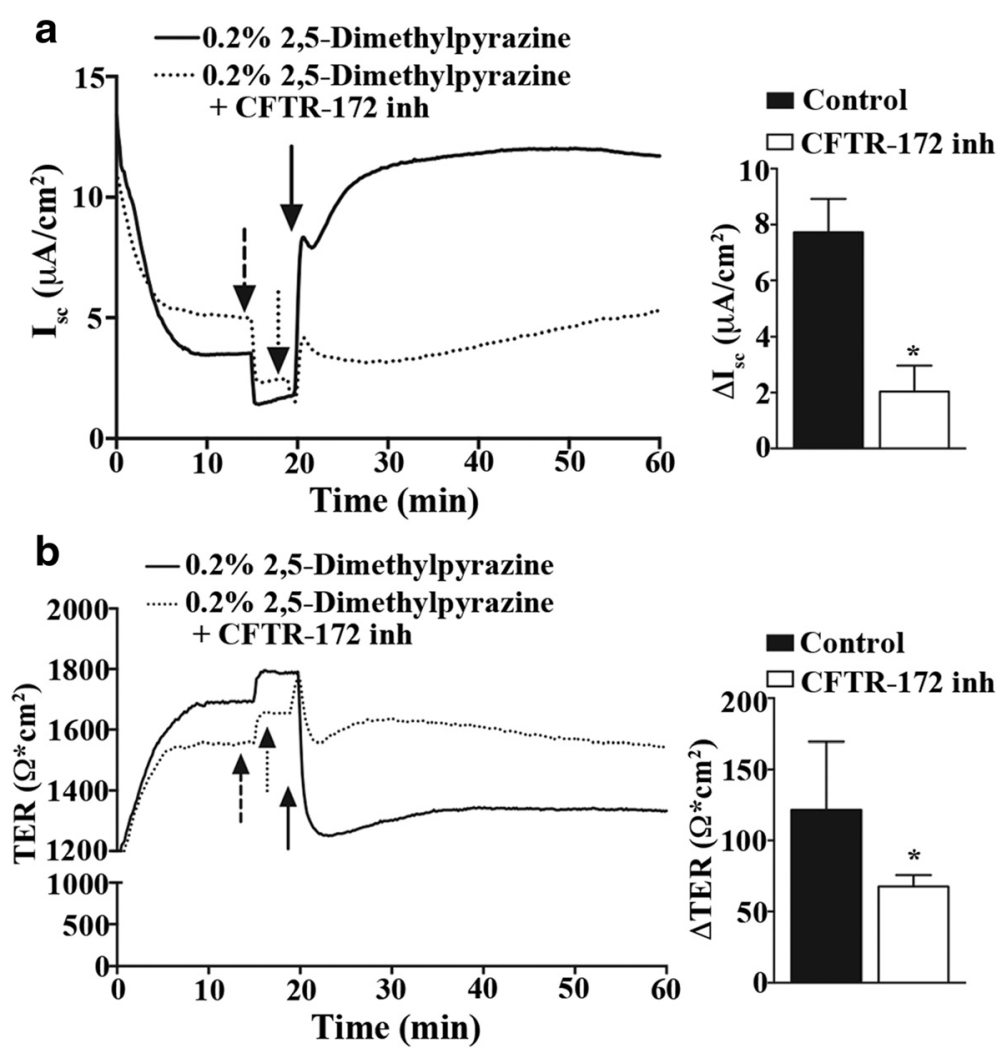

Fig. 4 2,5-Dimethylpyrazine activates apical ion efflux via CFTR. Primary MTE cells were voltage clamped in Ussing chambers and monitored for changes in $I_{\mathrm{sc}}$ and TER following addition of $0.2 \% \mathrm{v} / \mathrm{v} 2,5$-dimethylpyrazine. a Representative traces of $\mathrm{I}_{\mathrm{sc}}$ and $\mathbf{b}$ TER (left) from MTE cells treated with 2,5-dimethylpyrazine alone (solid line) or 2,5-dimethylpyrazine plus CFTR-172 inh [amiloride (dashed arrow), CFTR-172 inh (dotted arrow), 2,5-dimethylpyrazine (solid arrow)]. Quantification of $\mathrm{Isc}_{\mathrm{sc}}$ and TER (A-B right) of amiloride controls $(n=3)$ versus cells treated with amiloride and CFTR-172 inh $(n=4)$ are graphed. The addition of CFTR-172 inh significantly reduced the 2,5-dimethypyrazine-evoked apical ion efflux suggesting $\mathrm{Cl}^{-}$secretion via CFTR. *indicates significant difference $P<0.05$ in a one-way ANOVA with a Dunnett's Multiple Comparison Test

vanillin, that significantly altered airway epithelial cellular physiologic responses. Further characterization of 2,5dimethylpyrazine demonstrated a compromising effect on the response to common airway epithelial cellular signaling molecules in 16HBE14o- cells following a $24 \mathrm{~h}$ exposure. In primary MTE cells it evoked a rapid activation (min) of $\mathrm{Cl}^{-}$current through a cAMP/PKA/ CFTR-signaling pathway.

Early reports on e-cigarette toxicity focused primarily on identifying constituents in e-cigarette liquids and aerosols that are known to be harmful in conventional cigarettes (e.g., nicotine, tobacco-specific nitrosamines, aldehydes, volatile organic compounds) with less attention given to unique additives such as vegetable glycerin, propylene glycol and flavorings (for reviews see $[3,34,35]$ ). Limited studies on the pulmonary effects of short-term ecigarette use include increased airway resistance, decreased exhaled nitric oxide, and reported symptoms of cough [36-38]. An important argument from these initial studies is the emphasis for controlled research to properly evaluate all components in e-cigarette aerosols and their impact on lung cells and tissues. Careful studies that outline toxicity of flavorings are especially important considering that taste, including the large varieties of flavors, is a key consideration that contributes to the use of ecigarettes [36]. In this study we employed a high-capacity real-time cellular screening assay to identify those flavoring additives that demonstrate the potential to cause harm to the conducting airway epithelium. This high-capacity acute-liquid exposure model offers a means to delineate those flavoring constituents that are most detrimental from the multitude of constituents on the market. Such information can be used in future experiments that assess chronic aerosol exposures in vitro and in vivo to assess long-term effects.

Additives that allow for e-cigarette taste have been discussed as potential health hazards [13]. For example, an examination of flavoring constituents in 28 different e-liquid products found the presence of 141 different flavoring chemicals, some of which are known as allergenic compounds (e.g., eugenol and cinnamic aldehyde) [9]. An argument for the current use of flavorings in 

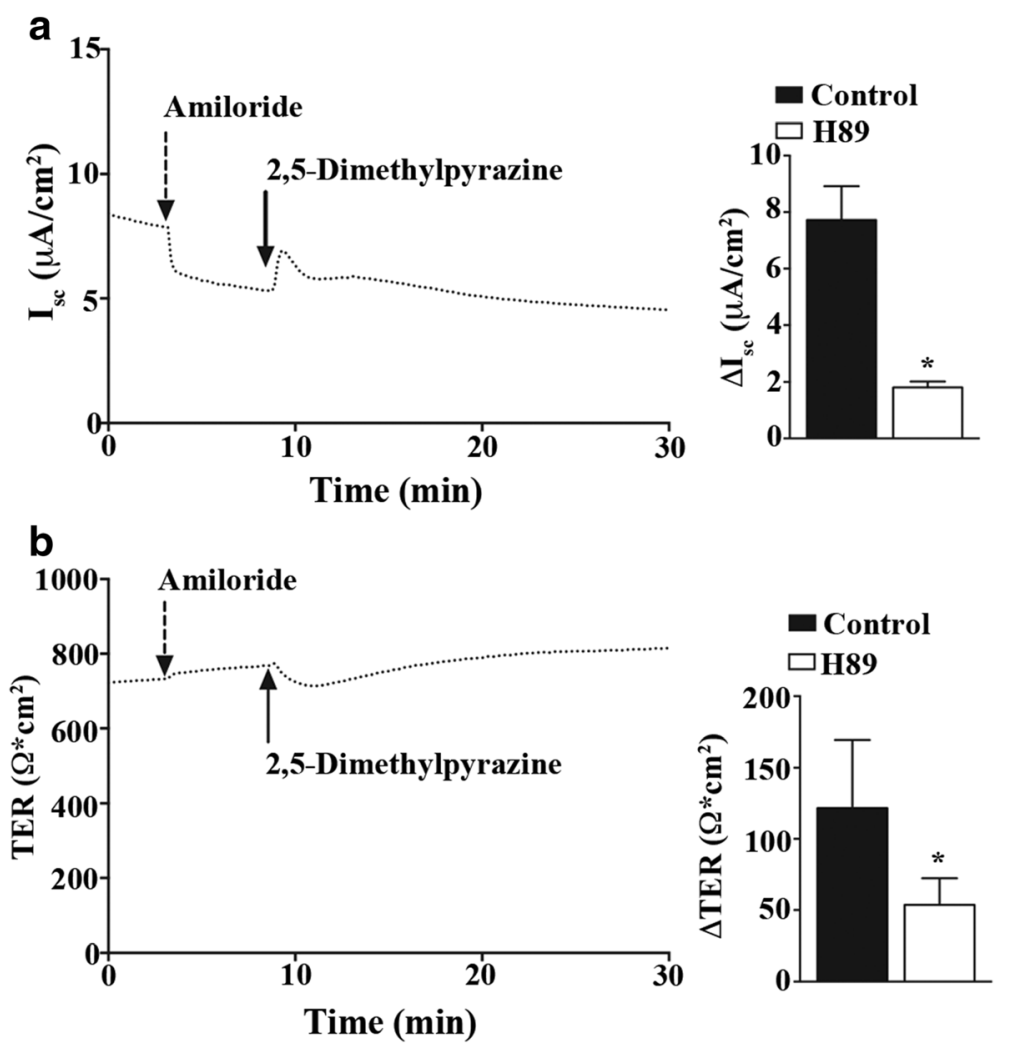

Fig. 5 PKA signaling is upstream of 2,5-dimethylpyrazine-evoked apical ion efflux. Primary MTE cells were voltage clamped in Ussing chambers and monitored for changes in $I_{s c}$ and TER following addition of $0.2 \% \mathrm{v} / \mathrm{v} 2,5$-dimethylpyrazine. a Representative traces of $\mathrm{I}_{\mathrm{sc}}$ and $\mathbf{b}$ TER (left) from MTE cells pre-treated with $\mathrm{H}-89$ followed by amiloride (dashed arrow) and 2,5-dimethylpyrazine (solid arrow). Quantification of $\mathrm{I}_{\mathrm{sc}}$ and TER (A-B right) of amiloride controls $(n=3)$ versus cells treated with amiloride and H89 $(n=3)$ are graphed. Significant block of apical ion efflux with H89 suggests 2,5-dimethypyrazine-evoked apical ion efflux is mediated via PKA signaling. *indicates significant difference $P<0.05$ in a one-way ANOVA with a Dunnett's Multiple Comparison Test

e-liquids is their prior approval by regulatory agencies for ingestion in small amounts. However, most chemicals used in flavorings have not been tested for respiratory toxicity via the inhalation route [39] and implications that ingestion safety is comparable to inhalation safety is, at best, misleading [40]. As an example, in the early 2000s several workers at microwave popcorn packaging plants across the U.S. developed bronchiolitis obliterans, a rare and irreversible obstructive lung disease that was later attributed to the artificial butter flavoring component diacetyl [12]. Despite the known inhalation toxicity of diacetyl, an examination of over 150 sweet flavored e-liquids found that $69.2 \%$ contained diacetyl in both the e-liquid and its corresponding aerosol. Further, almost half $(47.3 \%)$ of these e-liquids contained diacetyl at concentrations above the National Institute for Occupational Safety and Health (NIOSH) safety levels for occupational exposure [41]. It is clear that a need for research to characterize both the presence of toxic chemicals in e-cigarette flavorings and the potential adverse respiratory effects of exposure to those flavorings is needed [13]. The experimental setup in this study aims to identify those flavoring chemicals that disrupt airway epithelial function and the mechanisms by which this disruption occurs.

It is becoming increasingly evident that constituents in e-liquids can compromise various aspects of airway epithelial innate immunity. In the absence of nicotine, e-liquids caused increased pro-inflammatory cytokines (e.g., IL-6) and increased human rhinovirus infection in primary human airway epithelial cells [42]. In a separate study, e-liquids containing flavorings, especially those with fruit or sweet flavors, were more oxidative than those without flavorings, and thus potentially more damaging to the airway [43]. These authors also found that e-liquid aerosols increased secretion of IL-6 and IL-8 from human airway epithelial cells grown at an air/liquid interface. Our studies using high-capacity real-time cell analysis show the e-liquid chemical 2,5-dimethylpyrazine reduces the ability of 16HBE14o- cells to respond to forskolin-induced cAMP signaling and to a lesser extent exogenous ATP at subcytotoxic concentrations. These signaling pathways underlie 

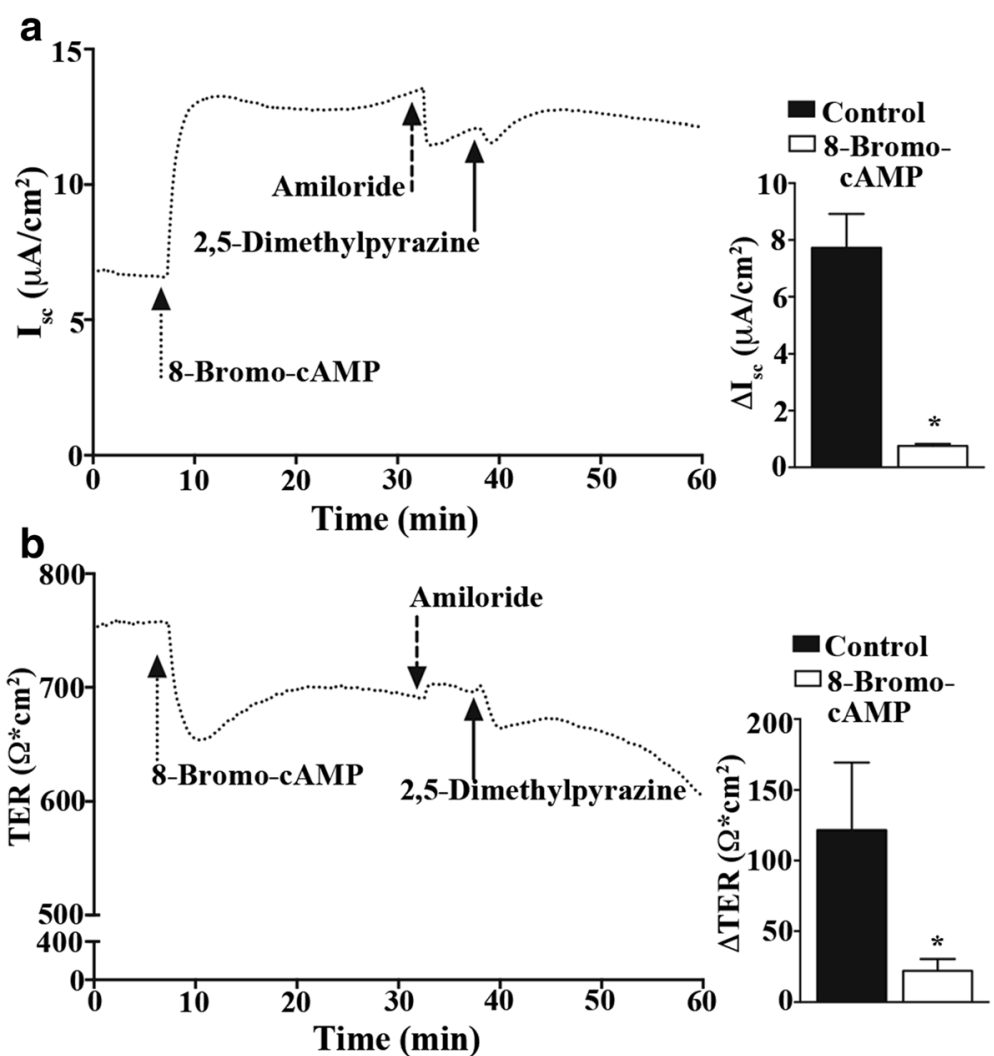

Fig. 6 Increased intracellular CAMP dampens 2,5-dimethylpyrazine-evoked apical ion efflux. Primary MTE cells were voltage clamped in Ussing chambers and monitored for changes in $I_{s c}$ and TER following addition of $0.2 \% \mathrm{~V} / \mathrm{v} 2,5$-dimethylpyrazine. a Representative traces of $\mathrm{I}_{\mathrm{Sc}}$ and $\mathbf{b}$ TER (left) from MTE cells pre-treated with 8-bromo-cAMP (dotted arrow) followed by amiloride (dashed arrow) and 2,5dimethylpyrazine (solid arrow). Quantification of $\mathrm{I}_{\mathrm{SC}}$ and TER (A-B right) of amiloride controls $(n=3)$ versus cells treated with 8-bromoCAMP and amiloride $(n=3)$ are plotted. The addition of the CAMP analog 8-bromo-cAMP significantly reduced apical ion efflux evoked by 2,5-dimethypyrazine suggesting it activates a receptor that increases CAMP production. ${ }^{*}$ indicates significant difference $P<0.05$ in a oneway ANOVA with a Dunnett's Multiple Comparison Test

several important physiological functions in the conducting airway epithelium.

Our biophysical studies are indicative of an acute 2,5dimethylpyrazine-evoked cAMP/PKA-signaling pathway that is consistent with the activation of an odorant receptor. Odorant receptors are not restricted to the upper airway and can have distinct physiologic function within the conducting airway as well as in other parts of the body (reviewed in [44]). 2,5-dimethylpyrazine is also a potent pheromone in both Drosophila [45] and in mice where it can lead to suppression of reproductive activities (reviewed in [46]). In this study we show that 2,5dimethylpyrazine activates cAMP/PKA signaling leading to transient changes in short-circuit current and transepithelial resistance via CFTR in mouse conducting airway epithelial cells. Chronic activation of CFTR signaling in vivo may alter CFTR expression and salt and water balance in the airway lumen that could negatively impact airway epithelial cell innate immune mechanisms such as mucociliary clearance.

\section{Conclusions}

E-cigarettes have become a common way to introduce flavorings via inhalation with unknown long-term health effects. It is established that flavored conventional cigarettes are more appealing among youth; 17 year olds three times more likely than 25 year olds to smoke a flavored cigarette [47]. Because of such findings, the 2009 Family Smoking Prevention and Tobacco Control Act banned flavored conventional cigarettes (excepting menthol and tobacco flavor) in an effort to reduce the number of young adults who become addicted to cigarettes [48]. The recent introduction of ENDS, including e-cigarettes has provided an avenue to re-introduce flavorings to inhalation devices. With the multitude of $\mathrm{e}$-cigarette flavoring choices in the marketplace it is essential that the constituents comprising these flavorings be assessed for human safety in order to inform regulatory authorities, healthcare providers and most importantly, e-cigarette users. Our approach to screen constituents for both 
cytotoxicity and subcytotoxic alterations in conducting airway epithelial cell physiology, followed by mechanistic studies, provides a successful strategy for understanding potential toxicants commonly used in e-cigarettes and other ENDS.

\section{Competing interests}

The authors declare that they have no competing interests.

\section{Authors' contributions}

Study concept and design: CLS, SB; data acquisition: CLS; analysis and interpretation of the data: CLS, SB; Writing of the manuscript and critical revision: CLS, SB. Both authors read and approved the final manuscript.

\section{Acknowledgements}

We would like to thank Scott W. Malm for his help with the MTS assay.

\section{Funding information}

This work was primarily supported by the National Institutes of Health $(\mathrm{NIH})$ Superfund Research Grant ES-04940 (SB) and the NIH Training Grant ES-007091 (CLS). This work was additionally supported in part by NIH Grant R01-NS-073664 (SB).

\section{Author details}

'Asthma and Airway Disease Research Center, Arizona Health Sciences Center, 1501 N. Campbell Avenue, Tucson, AZ 85724-5030, USA. ${ }^{2}$ Bio5 Collaborative Research Institute, Arizona Health Sciences Center, Tucson, AZ, USA. ${ }^{3}$ Department of Physiology, Arizona Health Sciences Center, Tucson, AZ, USA.

Received: 30 July 2015 Accepted: 13 December 2015

Published online: 17 May 2016

\section{References}

1. Johnson SR. Sparking controversy. Rise in e-cigarette use has public health experts questioning their safety, effectiveness as harm-reduction device. Mod Healthc. 2013;43:6-7. 12, 11.

2. E-cigs revolutionizing the tobacco industry. [http://www.smallcapfinancialwire. com/wp-content/uploads/2013/11/E-Cigs-Revolutionizing-the-TobaccoIndustry-Interactive-Model.pdf]. Accessed 22 Sept 2014.

3. Zhu SH, Sun JY, Bonnevie E, Cummins SE, Gamst A, Yin L, Lee M. Four hundred and sixty brands of e-cigarettes and counting: implications for product regulation. Tob Control. 2014;23 Suppl 3:3-9. iii.

4. Grana RA, Ling PM. "Smoking revolution": a content analysis of electronic cigarette retail websites. Am J Prev Med. 2014;46:395-403.

5. Hsu R, Myers AE, Ribisl KM, Marteau TM. An observational study of retail availability and in-store marketing of e-cigarettes in London: potential to undermine recent tobacco control gains? BMJ Open. 2013;3:e004085.

6. Rose SW, Barker DC, D'Angelo H, Khan T, Huang J, Chaloupka FJ, Ribisl KM The availability of electronic cigarettes in U.S. retail outlets, 2012: results of two national studies. Tob Control. 2014;23 Suppl 3:10-6. iii.

7. Goniewicz ML, Knysak J, Gawron M, Kosmider L, Sobczak A, Kurek J, Prokopowicz A, Jablonska-Czapla M, Rosik-Dulewska C, Havel C, et al. Levels of selected carcinogens and toxicants in vapour from electronic cigarettes. Tob Control. 2013;23(2):133-9.

8. Bahl V, Lin $\mathrm{S}, \mathrm{Xu}$ N, Davis B, Wang YH, Talbot P. Comparison of electronic cigarette refill fluid cytotoxicity using embryonic and adult models. Reprod Toxicol. 2012;34:529-37.

9. Hutzler C, Paschke M, Kruschinski S, Henkler F, Hahn J, Luch A. Chemical hazards present in liquids and vapors of electronic cigarettes. Arch Toxicol. 2014;88:1295-308.

10. Kavvalakis MP, Stivaktakis PD, Tzatzarakis MN, Kouretas D, Liesivuori J, Alegakis AK, Vynias D, Tsatsakis AM. Multicomponent analysis of replacement liquids of electronic cigarettes using chromatographic techniques. J Anal Toxicol. 2015;39(4):262-9.

11. Lisko JG, Tran H, Stanfill SB, Blount BC, Watson CH. Chemical composition and evaluation of nicotine, tobacco alkaloids, $\mathrm{pH}$, and selected flavors in E-cigarette cartridges and refill solutions. Nicotine Tob Res. 2015;17(10):1270-8.
12. Kreiss K, Gomaa A, Kullman G, Fedan K, Simoes EJ, Enright PL. Clinical bronchiolitis obliterans in workers at a microwave-popcorn plant. N Engl J Med. 2002;347:330-8.

13. Barrington-Trimis JL, Samet JM, McConnell R. Flavorings in electronic cigarettes: an unrecognized respiratory health hazard? JAMA. 2014;312:2493-4.

14. Vareille M, Kieninger E, Edwards MR, Regamey N. The airway epithelium: soldier in the fight against respiratory viruses. Clin Microbiol Rev. 2011;24:210-29.

15. Bals R, Hiemstra PS. Innate immunity in the lung: how epithelial cells fight against respiratory pathogens. Eur Respir J. 2004;23:327-33.

16. Beers MF, Morrisey EE. The three R's of lung health and disease: repair, remodeling, and regeneration. J Clin Invest. 2011;121:2065-73.

17. Diamond G, Legarda $D$, Ryan LK. The innate immune response of the respiratory epithelium. Immunol Rev. 2000;173:27-38.

18. Holgate ST. The sentinel role of the airway epithelium in asthma pathogenesis. Immunol Rev. 2011;242:205-19.

19. Puchelle E, Zahm JM, Tournier JM, Coraux C. Airway epithelial repair, regeneration, and remodeling after injury in chronic obstructive pulmonary disease. Proc Am Thorac Soc. 2006;3:726-33.

20. Gruenert DC, Finkbeiner WE, Widdicombe JH. Culture and transformation of human airway epithelial cells. Am J Physiol. 1995;268:L347-60.

21. Sherwood CL, Lantz RC, Burgess JL, Boitano S. Arsenic alters ATP-dependent $\mathrm{Ca}(2)+$ signaling in human airway epithelial cell wound response. Toxicol Sci. 2011;121:191-206.

22. Olsen CE, Liguori $A E$, Zong $Y$, Lantz RC, Burgess JL, Boitano S. Arsenic upregulates MMP-9 and inhibits wound repair in human airway epithelial cells. Am J Physiol Lung Cell Mol Physiol. 2008;295:L293-302.

23. Sherwood $C L$, Liguori $A E$, Olsen $C E$, Lantz RC, Burgess $J \mathrm{~L}$, Boitano $S$. Arsenic compromises conducting airway epithelial barrier properties in primary mouse and immortalized human cell cultures. PLoS One. 2013:8:e82970.

24. Sherwood CL, Lantz RC, Boitano S. Chronic arsenic exposure in nanomolar concentrations compromises wound response and intercellular signaling in airway epithelial cells. Toxicol Sci. 2013;132:222-34.

25. Otero-Gonzalez L, Sierra-Alvarez R, Boitano S, Field JA. Application and validation of an impedance-based real time cell analyzer to measure the toxicity of nanoparticles impacting human bronchial epithelial cells. Environ Sci Technol. 2012;46:10271-8.

26. Abassi YA, Xi B, Zhang W, Ye P, Kirstein SL, Gaylord MR, Feinstein SC, Wang $X, X u X$. Kinetic cell-based morphological screening: prediction of mechanism of compound action and off-target effects. Chem Biol. 2009;16:712-23.

27. Xi B, Yu N, Wang X, Xu X, Abassi YA. The application of cell-based label-free technology in drug discovery. Biotechnol J. 2008;3:484-95.

28. Flynn AN, Hoffman J, Tillu DV, Sherwood CL, Zhang Z, Patek R, Asiedu MN, Vagner J, Price TJ, Boitano S. Development of highly potent proteaseactivated receptor 2 agonists via synthetic lipid tethering. FASEB J. 2013:27:1498-510.

29. PONY: MSDS Report on Green Smoke E-Cigarettes Use Liquid (2011). [http:// www.greensmokedistribution.be/wp-content/uploads/2011/06/report.pdf]. Accessed 24 Sept 2014.

30. Tierney PA, Karpinski CD, Brown JE, Luo W, Pankow JF. Flavour chemicals in electronic cigarette fluids. Tob Control. 2015;25(e1):e10-5.

31. Counet C, Callemien D, Ouwerx C, Collin S. Use of gas chromatographyolfactometry to identify key odorant compounds in dark chocolate. Comparison of samples before and after conching. J Agric Food Chem. 2002;50:2385-91.

32. Buck $L$, Axel R. A novel multigene family may encode odorant receptors: a molecular basis for odor recognition. Cell. 1991;65:175-87.

33. Ronnett GV, Moon C. G proteins and olfactory signal transduction. Annu Rev Physiol. 2002;64:189-222.

34. Cheng T. Chemical evaluation of electronic cigarettes. Tob Control. 2014;23 Suppl 2:11-7. ii.

35. Pisinger C, Dossing M. A systematic review of health effects of electronic cigarettes. Prev Med. 2014;69:248-60.

36. Etter JF. Electronic cigarettes: a survey of users. BMC Public Health. 2010;10:231.

37. Marini S, Buonanno G, Stabile L, Ficco G. Short-term effects of electronic and tobacco cigarettes on exhaled nitric oxide. Toxicol Appl Pharmacol. 2014;278:9-15.

38. Vardavas Cl, Anagnostopoulos N, Kougias M, Evangelopoulou V, Connolly GN, Behrakis PK. Short-term pulmonary effects of using an electronic cigarette: impact on respiratory flow resistance, impedance, and exhaled nitric oxide. Chest. 2012;141:1400-6. 
39. Preventing Lung Disease in Workers Who Use or Make Flavorings [http://www.cdc.gov/niosh/docs/2004-110/pdfs/2004-110.pdf]. Accessed 23 Sept 2014.

40. Hallagan J: Safety Assesment and Regulatory Authority to Use Flavors: Focus on E-cigarettes. Flavor Extract Manufacturers Assoc United States 2015. http://www.femaflavor.org/sites/default/files/linked_files/ FEMAGRAS\%20Ecig\%20042516.pdf. Accessed 24 Sept 2014

41. Farsalinos KE, Kistler KA, Gillman G, Voudris V. Evaluation of electronic cigarette liquids and aerosol for the presence of selected inhalation toxins. Nicotine Tob Res. 2015;17:168-74.

42. Wu Q, Jiang D, Minor M, Chu HW. Electronic cigarette liquid increases inflammation and virus infection in primary human airway epithelial cells. PLoS One. 2014;9:e108342.

43. Lerner CA, Sundar IK, Yao H, Gerloff J, Ossip DJ, Mclntosh S, Robinson R, Rahman I. Vapors produced by electronic cigarettes and e-juices with flavorings induce toxicity, oxidative stress, and inflammatory response in lung epithelial cells and in mouse lung. PLoS One. 2015;10:e0116732.

44. Foster SR, Roura E, Thomas WG. Extrasensory perception: odorant and taste receptors beyond the nose and mouth. Pharmacol Ther. 2014;142:41-61.

45. Mathew D, Martelli C, Kelley-Swift E, Brusalis C, Gershow M, Samuel AD, Emonet T, Carlson JR. Functional diversity among sensory receptors in a Drosophila olfactory circuit. Proc Natl Acad Sci U S A. 2013;110:E2134-43.

46. Koyama S. Primer effects by conspecific odors in house mice: a new perspective in the study of primer effects on reproductive activities. Horm Behav. 2004;46:303-10.

47. Klein SM, Giovino GA, Barker DC, Tworek C, Cummings KM, O'Connor RJ. Use of flavored cigarettes among older adolescent and adult smokers: United States, 2004-2005. Nicotine Tob Res. 2008;10:1209-14.

48. Congress: Family Smoking Prevention and Tobacco Control and Federal Reitrement Reform. HR 1256 2009, Public Law:1175-1858. https:/www.gpo. gov/fdsys/pkg/PLAW-111 publ31/pdf/PLAW-111 publ31.pdf. Accessed 22 June 2009.

\section{Submit your next manuscript to BioMed Central and we will help you at every step:}

- We accept pre-submission inquiries

- Our selector tool helps you to find the most relevant journal

- We provide round the clock customer support

- Convenient online submission

- Thorough peer review

- Inclusion in PubMed and all major indexing services

- Maximum visibility for your research

Submit your manuscript at www.biomedcentral.com/submit

) Biomed Central 